\title{
Sustained water conservation by combining incentives, data and rates to effect consumer behavioural change
}

\author{
T. Hill \& G. Symmonds \\ Global Water Resources, USA
}

\begin{abstract}
Water scarcity is a looming problem and changing individual behaviour to compensate is a key constituent of sustainability. Behavioural change is a complex task requiring a combination of appeals, information, financial and social influences, and barrier elimination efforts. Implementing these concepts has been notoriously difficult, and it is only recently that advances in data access and presentment have allowed for a program that encourages behavioural change: providing a detailed, highly granular personalized understanding of consumption patterns, which, combined with financial incentives and social pressures, results in sustained resource conservation. Developing a rate design to complement the demand destruction and ensure the financial health of the utility is a vitally important component in achieving sustainability.

Keywords: water conservation, water sustainability, rate design, behavioural change, smart grid for water, rebate threshold rates, water demand destruction, price elasticity of water.
\end{abstract}

\section{Why do we pay for water?}

In the $13^{\text {th }}$ century, the City of London embarked on the construction of 12 "conduits" - designed to bring water from springs to cistern houses. From these cisterns, the water was piped to larger storage facilities equipped with cocks or taps for dispensing the water. In the early $14^{\text {th }}$ century, it was decided that brewers, cooks, and fishmongers should pay for the water they used, at the discretion of the keeper of the conduit, whose chief duty was to ensure that the water was not stolen for commercial purposes (Hansen [1]). Water "cobs" hand- 
delivered water on a fee-for-service basis from the cisterns to the City's residents. Water had acquired "value".

The growing population soon outstripped the existing conduits, and the polluted Thames River was increasingly less desirable as a source. The solution was to construct the "New River" aqueduct system to bring water from springs in the country-side to the City. This $60 \mathrm{~km}$ aqueduct was enormously expensive, requiring significant investment. The King provided half the funds (for which the royal household would receive "for ever the one halfe of the benefitt profitt"). A further 29 investors completed the funding and the aqueduct and distribution system was completed in 1613. Water had become a "business".

But it was not until 1633 that the New River Company began distributing profits to its shareholders. The infrastructure costs far exceeded the carrying capacity of the revenue derived from the system.

These examples demonstrate - from a very early point - the financial complexity of water service provision: infrastructure is massively expensive; investors demand returns; and ensuring the cost recovery of operating and maintaining delivery systems are essential in sustaining service.

The same holds true today. Water remains the most capital intensive utility business in which to operate. The National Association of Water Companies [2] notes that "for a water utility to earn a dollar, nearly $\$ 3.40$ must be invested in infrastructure, an intensity that approaches an average of three times that of other utility sectors".

\section{The certainty of demand destruction}

While most municipalities have means for recovering costs for the provision of water service, the underlying rate structures and the principles and goals vary widely. Today, water utilities must operate in the reality of decreasing supplies, increasing costs and revenue reductions.

Water utilities must now permanently destroy demand to survive resource scarcity. How to do this without also destroying the financial viability of the utility will be the fundamental problem of $21^{\text {st }}$ century utility management. Particularly since the infrastructure requirements for water sustainability (water reuse, dual water mains, control systems, treatment) and water suitability (treatment, etc.) will continue to increase the cost of providing service to consumers.

\section{Behaviour modification tools to achieve financial and water resource sustainability}

Changing behaviour is a complex task. Dietz et al. [3] described this when referring to behavioural changes associated with carbon reduction. The applicability to water conservation is equally as strong. To be successful, water managers will need to touch consumers many times and in many ways: 
Mass media appeals and informational programs can change attitudes and increase knowledge, but they normally fail to change behaviour because they do not make the desired actions any easier or more financially attractive. Financial incentives alone typically fall far short of producing cost minimizing behaviour...However, interventions that combine appeals, information, financial incentives, informal social influences, and efforts to reduce the transaction costs of taking the desired actions have demonstrated synergistic effects beyond the additive effects of single policy tools (emphasis added, Dietz et al. [3]).

It is clear that to be successful, it is imperative to use the influence of education, information and incentive packages to change behaviour. And they have to be easy to implement and use for the consumer.

While the majority of the reasons to conserve have historically been altruistic, there now exist powerful tangible reasons for conservation, including real scarcity, growing populations and a desire to reduce costs. Further, if a financial incentive can be developed such that consumers are rewarded for conservation, the untapped power of positive reinforcement can be brought to bear on water use.

However, in many cases, rate designs are such that achieving conservation via increased consumer costs inevitably result in decreasing revenues for the utility. Establishing a rate structure that destroys demand without destroying the utility financially is critical for our water utilities to continue to manage this vital resource.

\section{The certainty of increasing rates}

Increasing demand, decreasing quality, increasingly stringent water quality requirements, deteriorating infrastructure and the future impact of climate induced variability are straining water resources, and the utility's financial capacity to address them. The cost of acquiring, producing, treating and delivering water is going up. The result: higher prices for consumers. Ironically, conservation does not mean prices will decrease for all consumers. Properly capitalized, financially solvent utilities are the cornerstone for the investment we need in a sustainable water future.

The question is whether regulators, or city councils, have the will or the ability to execute on a strategy that brings both financial stability and conservation at the same time. As we know, the result of price increases will be public outcry - but does it have to be? As Scott Hempling [4] of the National Regulatory Research Institute (NRRI) points out:

Those years-long rate freezes lull the public into thinking rate stability is an entitlement. When, after ten years of below-cost rates, the commission realigns rates with cost, we know what happens: (1) Voters don't offer thanks for the prior windfall; they protest the new levels, loudly. (2) Politicians fan these flames, making rational policymaking 
difficult. (3) The compromise arrives, usually more pain deferral than pain sharing, thus skirting the underlying problem (the public's lack of acceptance that utility costs, like all costs, rise). What works in politics - mediating between positions - rarely works in regulation, where the midpoint between two wrong answers is a third wrong answer.

The problem is that regulators (be they public utility commissions or City Councils) do not regulate consumers, but utilities. And if conservation is a public interest goal, they must provide the incentives to consumers through utilities. Part of that program is getting the prices and price signals right so as to eliminate waste, but also to serve the competing goals of consumer protection, utility financial stability and achieving water sustainability.

Hempling [4] continues: "Rate design is the key to consumer protection. To moderate cost increases, we must moderate the demands that cause costs. Rate design offers the double anti-oxymoron: price increases are consumer protection, because (1) price increases change behaviour and (2) behaviour change yields lower total costs."

\section{Price elasticity of water}

One of the conundrums of developing conservation oriented rates is the fact that at current prices, demand is unresponsive to price. However, Olmstead [5] notes that any estimate of price elasticity "represents an elasticity in a specific range of prices". That is, if the total cost is low, the response to increasing costs will be low. As prices increase - and they surely must - responsiveness increases. This presents some interesting rate design issues, as elasticity will begin to occur at higher tier levels within the same classes of consumers.

In general, the long term impacts of price elasticity are greater than the shortterm elasticity. This is a result of the time required for consumers to react to the implementation of higher rates, and to the completion of the necessary modifications (behavioural and infrastructure) to achieve reductions in consumption. For example, if a large step-function increase in rates is applied, consumers may immediately be able to reduce some discretionary consumption, resulting in a dip in demand. However, to complete the reaction, in some cases retrofitting fixtures, replacing landscaping, increasing internal water re-use will occur, and that process will take time.

On average, a $10 \%$ increase in the marginal cost of water can be expected to reduce residential demand by $3-4 \%$ in the short run. In the long term, such an increase could be expected to yield a $6 \%$ decrease in demand (Olmstead and Stavins [5]).

Clearly, price sensitivity to water resulting in demand reductions will reduce utility revenue. A true conservation-oriented rate structure must take into account this revenue destruction that is concomitant with demand reduction. 


\section{Rate design}

The primary purpose of any rate design is that it generates the necessary revenue for the utility in a manner that is fair and based on the cost of providing service (Rubin [6]).

Various forms of rate structure have been developed and employed, not all of which satisfy Bonbright's [7] and Phillips' [8] effective rates criteria. In municipal applications, water service has been provided under many differing cost recovery mechanisms, notably:

- Free

- $\quad$ Fixed Fee (no volumetric rate)

- Uniform Rates (fixed base rate + static volumetric rate)

- Declining Block Rates (fixed base rate + decreasing volumetric rates)

- Pyramid Rates (fixed base rate + increasing volumetric rates for small users and decreasing volumetric rates for larger users)

- Inclining Block Rates (fixed base rate + increasing volumetric rates)

- Water Budget-based Rates (based on housing population and landscaping)

\subsection{Free water}

Clearly free water is no longer an option - although it still exists in many jurisdictions. And in reality it has never been free to constituents as the costs of operating any municipal infrastructure are recovered through some revenue stream. The primary problem with free water is that it perpetuates the invisibility of water while simultaneously reinforcing the myth that water is ubiquitous and continuously available.

\subsection{Fixed fee}

Prior to metering (and in some cases even with metering), water charges were assessed on a flat fee structure. All consumers paid the same fees regardless of usage (e.g. \$20/month). While this has the benefit of generating revenue for the utility and increasing the awareness of water for the general public, there is no incentive for the consumer or the utility to reduce usage.

\subsection{Uniform rates}

Uniform rates provide for a small "fixed" fee with a non-variable volumetric charge. This rate structure provides no incentive to conserve (that is, there are no additional charges for using more) and the small fixed component drives the utility to encourage consumption as a means to ensure revenue or even to generate incremental revenue. 


\subsection{Declining block rates}

Declining block rates are employed to provide volumetric breaks to large consumers under the premise that the marginal cost of providing large amounts of water to a small number of users is lower than providing the infrastructure, operations and maintenance for a large number of lower consumption users.

However, in many cases, large water users can actually define a system's necessary capacity (and thus the cost of the system's infrastructure). As an example, if you consider that a large industrial consumer may demand short periods of 2000 gallons per minute, this is the equivalent of the peak hour flow from 3400 single family dwellings. Notwithstanding that the demand may be intermittent, the infrastructure needs to be there.

Regardless, the declining block model encourages the consumer and the utility to increase consumption - the consumer because his or her marginal cost declines with use, and the utility must sell more water at a lower cost to ensure the revenue requirement is met.

\subsection{Pyramid rates}

Pyramid rates combine Inclining Block Rate structure and Declining Block Rate structures in an attempt to eliminate the detrimental aspects of each. In this case, consumers are charged higher volumetric rates as consumption increases to a specified point, and then volumetric costs decrease.

Such a system does not promote conservation for the higher consumer. Wang et al. [9] notes "It is likely not accurate, however, to consider pyramid block rates to be water conservation-oriented rates, as they result in the highest consumers within the commercial class paying less per unit that those who use less."

\subsection{Inclining block rates}

With inclining block rates, more consumption means higher cost. While recognized as a water conservation rate structure, the Inverted Block Rate (IBR) structure encourages the utility to maintain consumption levels because the marginal revenue decrease from conservation occurs at the higher rate. In addition, IBRs are typically designed with low price signals (that is small tier increments) and broad tier ranges that lose effectiveness quickly in the consumption spectrum.

\subsection{Water budget-based rates}

Water budget-based rates define "normal" usage for a particular property based upon actual water use, size of meter and the customized water budget for the property. Consumers whose water use remains within their water budgets are billed the lower rates, and consumers who exceed their budgets are billed at higher consumption rates. 
The water budget is calculated for residential customers based upon surveys conducted of each customer's lot size and landscaped area, the number of residents in each home and localized weather data. Water budgets change with seasons. For commercial applications, water budgets are established on rolling averages of use.

A key difficulty in establishing water budgets is the necessity to frequent and up-to-date property information with respect to population and landscaping, increasing manpower commitments to manage the program.

\subsection{Summary}

All of the "standard" rate designs suffer from significant shortfalls when it comes to encouraging conservation while preventing utility financial distress. A new form of rate design, the tunable Rebate Threshold Rate (RTR) structure, alleviates these problems.

\section{Rebate Threshold Rate (RTR) structure}

Today, the altruistic desire to conserve is being overtaken by real practical requirements. Water scarcity, dwindling historic supplies, environmental diversions, population growth, and regulatory requirements all are conspiring to send a clear message - use less water tomorrow; and even less the day after that. However, the decisions that drive conservation are most often based on economic factors at the household level. The Rebate Threshold Rate (RTR) structure is designed to reflect this reality and to maximize the behavioural change opportunities for consumers. This is achieved by the adoption of three basic elements in the RTR:

- Volumetric Rebate and increasing volumetric charges in higher tiers to compensate;

- Increasing the number and granularity of tiers; and

- Achieving some measure of rate decoupling by increasing the fixed rate component.

\subsection{Volumetric rebate}

The volumetric rebate allows for residential customers who achieve real, immediate reductions in water consumption to realize an immediate reduction in their volumetric charges. Any time a customer achieves a consumption level below the Rebate Threshold, the customer is entitled to receive a reduction in volumetric charges (commodity charges). That reduction is typically $45 \%$ to $65 \%$ (fig. 1). This reduction is shown as a "conservation rebate" on the consumer's invoice.

The rebate threshold is established at a percentage of the average residential consumption for a specific period, and remains static between changes in rates, but it could easily be tuned annually or as desired. As water elasticity occurs 
RTR TIER DESIGN

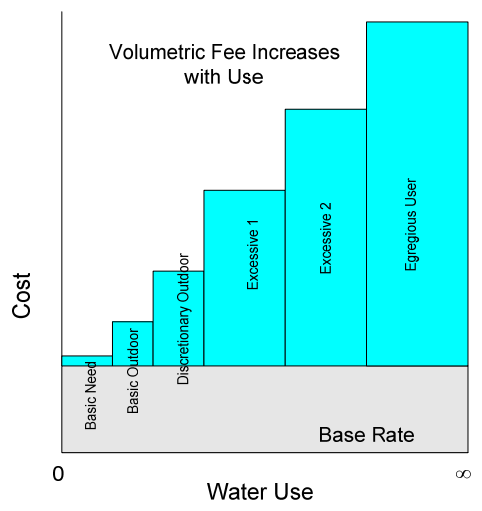

CONSUMER COST

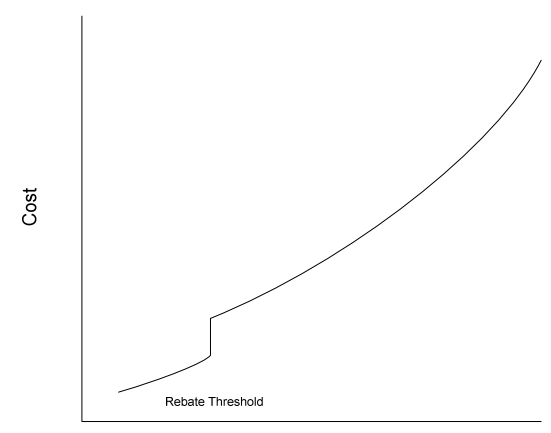

Consumption

Figure 1: $\quad$ Rebate threshold rate structure.

over longer timescales, it is important to allow people sufficient time to develop personal water management techniques and practices to maximize their benefit.

A key supporting element of the RTR rate design is consumer feedback with sufficient granularity for the consumer to make changes in near-real time to control their costs.

\subsection{Volumetric tiers}

An increase in the number and granularity of tiers in the RTR structure allows customers to manage their usage, even if they are not below the Rebate Threshold and still achieve meaningful cost reductions. Further, it ensures that there are greater financial disincentives as water use increases.

Today, utilities typically employ a two or three-tier rate structure in an IBR design. The downside is that by limiting rate design to two or three tiers, those tiers are by necessity broad, limiting the ability for customers to manage their consumption in a cost avoidance manner. This means that customers have fewer opportunities to manage themselves to a lower tier. In addition, the financial incentive for conservation in an IBR design ends far below a customer's consumption, meaning there is no increased marginal cost to carry on with that behaviour-modifying activity.

Increasing the number of tiers offers a number of "gates" through which the consumer has the option of passing, or not, placing the control of the consumer's volumetric costs squarely in the hands of the consumer. In the case of a two- or three-tier system, the gates are passed too quickly and with little fanfare. The incentive to conserve through the traditional two- or three-tier price points is lost immediately upon entering the final tier. With a six-tier design, customers have an incentive to think about different water price points throughout the consumption spectrum (fig. 1).

In a six-tier RTR system, with the tiers established across effective thresholds, the customer has an opportunity, through active management, to 
maintain his or her consumption in a lower tier, and receive the benefit of the lower rate. Also with a six-tier system, finer modifications to rates can be achieved, saving customers money, and reinforcing the conservation message. Tiers can also be tuned to specific users, if desired, building on the "individuality" of the water budget-based rate structure.

\subsection{Revenue decoupling}

The Monthly Minimum Charge (or base rate or basic charge), allows the utility to effect meaningful, measurable and repeatable resource conservation without the implosion of utility revenue. Historically, support for conservation in the water utility business has been suspect: the utility knows that by encouraging its customers to use less, there is a real chance of revenue reduction, and potentially a conflict with "used and useful" doctrines as infrastructure may be seen as "unnecessary" in the context of a reduced demand.

To achieve conservation goals, we must break the cycle of selling more water. By allowing for the recovery of fixed costs with a bias toward the monthly minimum, we can achieve both goals.

From a theoretical economic perspective, the provision of water service can be separated into infrastructure (fixed) and delivery (variable) costs. In practice, the dividing line is not as neat. Nor should it be, particularly as the goal of rates shifts from specific cost recovery, to behavioural modification for the purposes of resource management.

Attempting to definitively separate infrastructure and delivery costs can lead to some unintended consequences. As utility plant depreciates, there can be a tendency for regulators and city councils to reduce the "fixed" component of water rates (with the belief that full cost recovery has been achieved) and recover more utility costs through the "variable", or volumetric component. Under this condition, the utility loses its incentive to encourage conservation, because a reduction in use means an immediate reduction in revenue. Further, there is no incentive for the utility to invest in replacing aging infrastructure.

Clearly, if the bias is toward $100 \%$ cost recovery via monthly minimum charges and no increasing commodity rate, there is no incentive for the consumer to conserve. Conversely, biasing rate structures to recover all costs via the commodity rate creates a strong economic disincentive for the utility to promote water conservation. By establishing a reasonable apportionment of costs to the monthly minimum and the commodity costs, both goals are achieved.

By generating approximately $65 \%$ of the revenue from monthly base fees (fig. 2), the financial viability of the utility can be assured. This is a key differentiator between the RTR and standard rate designs. The RTR design requires that the higher users contribute more as a function of consumption, but also that more of the revenue is achieved through the fixed component. This is a recognition that the fixed costs do not simply represent infrastructure, but the "operational availability" of infrastructure. 


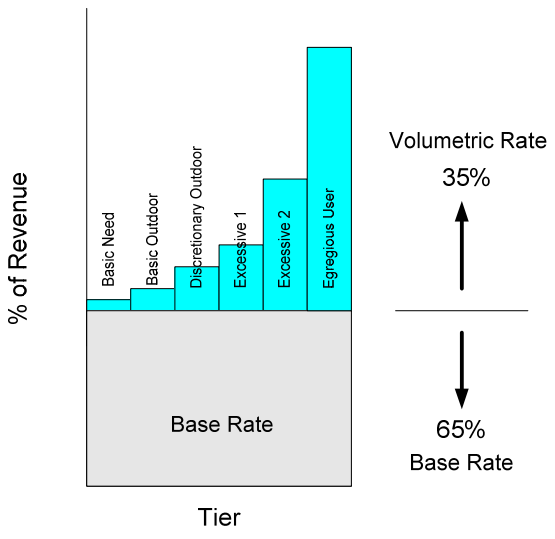

Figure 2: $\quad$ Rebate threshold rate structure revenue allocations.

\section{Rate tuning - the carrot and stick}

The RTR structure allows for utilities and regulators to tune rates to achieve specific objectives. For instance, the rebate threshold can be incrementally lowered to drive consumption down. Or the granularity of tiers can be altered to ensure that lifeline water supplies always remain within access for low-income households. Or the utility can establish tier levels to derive more revenue from egregious users to fund conservation infrastructure projects. Or the utility can fine tune the "gates" for individual users.

TUNING THE RTR STRUCTURE

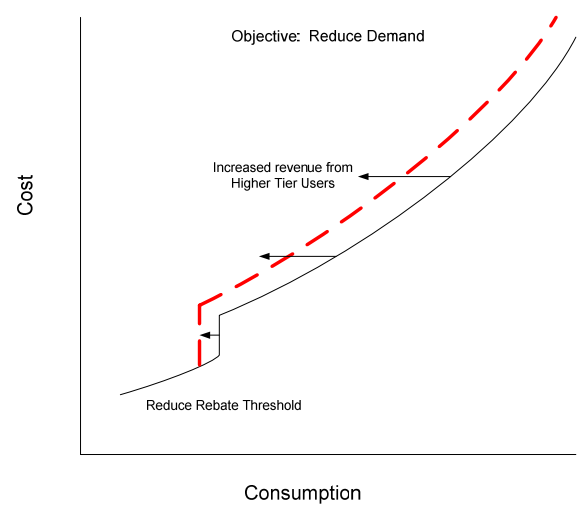

Figure 3: Adjusting demand with the rebate threshold rate structure. 
As an example, if a utility desires to fund conservation infrastructure (e.g. recycled water distribution systems, Smart Grid for Water installation etc), it can increase the cost of higher tier water (tiers 4, 5 and 6) while maintaining lower tiers to ensure accessibility to water for all.

Alternatively, a utility may wish to reduce overall demand due to dwindling resource availability. In this case, the utility can shift the rebate threshold to a lower volume, providing an economic incentive for all users to reduce demand. Users around the rebate threshold will adjust usage to maintain their economic incentive, and users above the threshold will adjust usage to remain in lower cost tiers (fig. 3).

\section{Data requirements}

To be effective, the RTR structure requires that consumers be afforded access to highly granular, near-real-time data. The consumer needs to have the opportunity to review daily consumption, and make an economic decision based on that information. But equally important is the data presentment or in Dietz's parlance, "informal social influences". To be successful, a conservation program must get the data out to customers and make the change financially beneficial to the consumer. But even further, people must be given the "geo-temporal" context of their consumption:

- How much water do I use?

- How do I fare compared to my street, my neighborhood, my city?

- How much water should I use?

- $\quad$ Based on weather data and evapotranspiration calculations - how much should I have used outside?

Robert Cialdini [10], a psychologist at Arizona State University, recently noted: "People don't recognize how powerful the pull of the crowd is on them... We can move people to environmentally friendly behaviour by simply telling them what those around them are doing."

A recent study completed by California State University (Schultz et al. [11]) indicated that through the provision of instantaneous feedback on water consumption, average water consumption reductions in the order of $14 \%$ can be achieved.

Combining price structure and appropriate signals, financial incentives, information and subtle societal pressures, consumer behaviour can be altered to the point where he or she asks the questions: "Do I need to use that gallon of water? and "Am I prepared to jeopardize my financial incentive to use the next gallon of water?"

\section{Conclusions}

The cost of water is going up while the availability of the resource is declining. In order to facilitate the survival of our natural resources, and our water utilities, 
a new pathway on rate design and cost recovery needs to be developed. The Rebate Threshold Rate structure allows communities to determine conservation goals and tune rates to achieve them, while ensuring the financial stability of the water utility. By employing education, incentives and information in easily digestible and actionable forms, utilities can achieve sustained, meaningful reductions in demand, water sustainability and financial sustainability.

\section{References}

[1] Hansen, R.D., "Water-related Infrastructure in Medieval London" p.4-5, www.waterhistory.org

[2] National Association of Water Companies, "Price, Cost, Value"

[3] Dietz, T., Gardner, G., Gilligan, J., Stern, P.C., Vandenbergh, M.P., Household actions can provide a behavioral wedge to rapidly reduce US carbon emissions. Proceedings of the National Academy of Sciences, 106(44), pp. 18452-18456, 2009

[4] Hempling, S., "Low Rates, High Rates, Wrong Rates, Right Rates", National Regulatory Research Institute, 2009

[5] Olmstead, S.M., Stavins, R., Comparing price and nonprice approaches to urban water conservation, Water Resources Research, 45, W04301

[6] Rubin, S.J., What does water really cost? Rate design principles for an era of supply shortages, infrastructure upgrades and enhanced water conservation, National Regulatory Research Institute, July 2010

[7] Bonbright, J.C., Principles of Public Utility Rates (New York, NY, 1961) p. 291

[8] Phillips, Jr., C.F., The Regulation of Public Utilities: Theory and Practice (Arlington, VA, 1993), pp. 434-435

[9] Wang Y.-D., Smith W.J. and J. Byrne, Water Conservation-Oriented Rates: Strategies to Extend Supply, Promote Equity, and Meet Minimum Flow Levels, American Water Works Association, Denver, Co., p. 12, 2005

[10] Simon, S. "The Secret to Turning Consumers Green", Wall Street Journal, 18 October 2010

[11] Schultz, W., DeCianni, W., Roldan, A. "Water Conservation Pilot", California State University, San Marcos 